\title{
Avaliação da Eficiência de Um Sistema de Tratamento por Wetland Construído Aplicado ao Efluente de um Frigorífico de Suínos
}

\section{Evaluation Of Constructed Wetland Treatment System Effectiveness Applied To A Swine Slaughterhouse Effluent}

\author{
Bruna Souza Dos Santos ${ }^{1}$; Poliana Ferreira da Costa ${ }^{2}$, Eduardo Eyng³; Carla Daniela Câmara ${ }^{4}$
}

\begin{abstract}
Resumo
Este trabalho apresenta os resultados obtidos com um sistema de tratamento por wetland construído, aplicado ao efluente de um frigorífico de suínos. Implantou-se um módulo experimental preenchido com uma camada de solo, seguido de pedra brita e areia como material filtrante e na camada superior foi plantado a macrófita Juncus effusus. O sistema foi adaptado com um controlador de nível que junto a um sistema de recalque promovia a recirculação do efluente. Este experimento foi desenvolvido utilizando-se um tempo de retenção hidráulica de 96 horas, sendo que amostras foram coletadas a cada 24 horas para posteriores análises físico-químicas. Os resultados obtidos foram promissores, sendo obtido 98,4\% de remoção da DQO - Demanda Química de Oxigênio após 96 horas de tratamento. Além disso, também houve uma diminuição da condutividade elétrica do efluente, possivelmente, devido ao consumo de nutriente pelas plantas.
\end{abstract}

Palavras-chave: Efluente agroindustrial. Leito cultivado. Desempenho de Tratamento.

\begin{abstract}
This paper presents the results obtained with a treatment system by constructed wetland, when applied to effluent from a swine slaughterhouse. The experimental module was filled with a soil layer, followed by crushed stone and sand as filtering material and the upper layer was planted macrophyte Juncus effusus. A level controller and a pump provided the effluent recirculation in experimental module. This experiment was conducted for a hydraulic retention time of 96 hours, in addition, samples were collected every 24 hours for subsequent physical-chemical analyzes. The results were promising, was obtained $98.4 \%$ removal of COD - Chemical Oxygen Demand after 96 hours of treatment. Moreover, there was also a decrease in the electrical conductivity of the effluent, possibly due to nutrient consumption by the plants.
\end{abstract}

Keywords: Agro-industrial effluent. Constructed Wetland. Treatment performance.

\footnotetext{
1 Tecnóloga em Gestão Ambiental pela Universidade Tecnológica Federal do Paraná (UTFPR), campus Medianeira. Mestre em Tecnologias Ambientais pela Universidade Tecnológica Federal do Paraná. Doutoranda em Engenharia Química, Universidade Estadual do Oeste do Paraná (UNIOESTE). brusouzasantos@hotmail.com

2 Tecnóloga em Gestão Ambiental pela Universidade Tecnológica Federal do Paraná (UTFPR). Mestre em Agronomia pela Universidade Estadual do Oeste do Paraná (UNIOESTE). Doutoranda em Ciência e Tecnologia Ambiental, Universidade Federal da Grande Dourados (UFGD). poliferreiradacosta@hotmail.com

3 Engenheiro Químico pela Universidade Estadual do Oeste do Paraná. Doutor em Engenharia Química pela Universidade Estadual de Campinas. Professor do Programa de Pós-Graduação em Tecnologias Ambientais (PPGTAMB) da Universidade Tecnológica Federal do Paraná (UTFPR). eduardoeyng@utfpr.edu.br

4 Engenheira Agrônoma pela Universidade Estadual de Londrina. Doutora em Engenharia Hidráulica e Saneamento pela Universidade de São Paulo (USP). Professora do Programa de Pós-Graduação em Tecnologias Ambientais (PPGTAMB) da Universidade Tecnológica Federal do Paraná (UTFPR). camara@utfpr.edu.br
} 


\section{Introdução}

O desordenamento na gestão e utilização dos recursos hídricos tornou-se, nos dias atuais, uma preocupante problemática social, requerendo da comunidade científica e dos órgãos gestores e fiscalizadores, além de soluções, direcionamento técnico e científico para amenização da escassez e todo desequilíbrio que ela acarreta (SOUZA et al., 2015).

$\mathrm{O}$ setor da suinocultura vem contribuindo significativamente para o crescimento econômico do país. Segundo dados da Associação brasileira de proteína animal (ABPA, 2014), o Brasil está entre os 10 maiores produtores de suínos do mundo, com 3 milhões de cabeças abatidas em 2014. Porém, o uso da água no processamento de alimentos gera grandes quantidades de efluentes líquidos, que necessitam ser tratados antes do seu lançamento em corpos hídricos receptores (MATOS et al., 2010).

Neste sentido, os problemas ambientais ocasionados pela atividade de frigoríficos estão diretamente relacionados com os seus despejos ou resíduos oriundos das diversas etapas do processamento industrial, pois a grande demanda de água requerida gera uma elevada quantidade de efluentes líquidos a serem tratados (SCHOENHALS; SENA; JOSÉ, 2006).

Os efluentes das suiniculturas são caracterizados por um elevado teor de sólidos suspensos totais e matéria orgânica, elevada quantidade de demanda bioquímica de oxigénio (DBO) e elevados teores de azoto e fósforo, bem como uma elevada população microbiana. Possuem também macro e micronutrientes, como fósforo $(\mathrm{P})$, potássio $(\mathrm{K})$, cálcio $(\mathrm{Ca})$, magnésio $(\mathrm{Mg})$, zinco $(\mathrm{Zn})$, cobre $(\mathrm{Cu})$ e ferro (Fe) (PENA, 2014).

Mediante a necessidade de alternativas para a descontaminação ambiental, uma opção é a utilização da fitorremediação, a qual consiste em uma técnica que emprega sistemas vegetais fotossintetizantes e sua microbiota como agentes remediadores (GOUVEIA; MACRUZ; ARAÚJO, 2015).
Considerada uma planta macrófita o Juncus effusus tem sido testado como planta fitorremediadora (PRATAS et al., 2010). Pertence à família Juncaceae, de plantas herbáceas, hábito cespitoso e terrenos brejosos. O gênero nativo Juncus ocorre predominantemente no Sul e Sudeste do Brasil, em áreas de maior altitude (SOUZA; LORENZI, 2005). A fitorremediação com macrófitas é uma boa alternativa para a recuperação de ambientes contaminados com efluentes. Essas plantas apresentam boa capacidade de absorção de contaminantes e têm uma rápida multiplicação, favorecendo a fitorremediação numa maior parte do meio (PEREIRA, 2010).

Os diferentes elementos atuantes no processo de tratamento nos wetlands construídos ou leito cultivados, tais como os critérios de dimensionamento e operação (carga orgânica, taxa hidráulica e regime de alimentação), a composição do material filtrante e as macrófitas empregadas, possuem particularidades vinculadas à localidade do estudo e/ou aplicação da unidade de tratamento (SEZERINO et al., 2015).

Os sistemas de wetlands construídos são sistemas projetados que utilizam tecnologia com o objetivo de reproduzir os sistemas de wetlands naturais (BEDA, 2011). Consiste em um sistema artificial, projetado para utilizar plantas aquáticas (macrófitas) em substratos (areia, solo, ou cascalho), onde ocorra proliferação de biofilmes que acumulam populações variadas de microrganismos que, através de processos biológicos, químicos e físicos, realizam o tratamento de águas residuárias (SOUZA et al., 2000).

Para minimizar os riscos das águas residuárias, reduzindo também a contaminação microbiológica, os wetlands construídos com plantas macrófitas são considerados como um método de tratamento que utiliza tecnologia simples, sendo um sistema robusto, de baixo custo e simplicidade de operação e manutenção (BRASIL; MATOS, 2008).

A maioria dos dados de desempenho disponíveis para os sistemas de wetlands construídos são de climas 
temperados, mas a eficácia do tratamento deverá ser significativamente maior em áreas tropicais devido às altas temperaturas e associado a maior atividade microbiana (TRANG et al., 2010). Os wetlands construídos têm sido utilizados com sucesso na remoção de nitrogênio e outros poluentes de águas residuais. Esta remoção é baseada em processos físicos, químicos e biológicos (TOET et al., 2003).

Neste sentido, o presente trabalho teve como principal ojetivo avaliar a eficiência do tratamento por sistema de wetland construído com alimentação superficial aplicado ao efluente de um frigorífico de suínos, a fim de determinar o grau de descontaminação do efluente através de um comparativo das análises realizadas na entrada e na saída do sistema, sendo considerados os parâmetros de $\mathrm{pH}$, condutividade elétrica e DQO.

\section{Metodologia}

$\mathrm{O}$ efluente industrial destinado aos testes experimentais foi cedido por um frigorífico de suínos localizado no oeste do Paraná.

O sistema de tratamento de efluentes, empregado pela indústria, constitui-se inicialmente de um pré-tratamento com o uso de grades de retenção, destinado a eliminar os materiais grosseiros que tiveram acesso à rede coletora. Posteriormente é realizado o tratamento primário, que visa eliminar partículas pequenas em suspensão. São utilizadas peneiras para remover grande parte dos sólidos, reduzindo a carga destes no efluente industrial e, portanto, reduzindo gastos de manutenção e aumentando a eficiência dos tratamentos posteriores. Nesta etapa do tratamento ocorre a separação do efluente em duas linhas diferentes, dependendo dos resíduos gerados: Linha Vermelha, composta por resíduos da indústria em geral; e Linha Verde, constituída pelos resíduos da pocilga, parte da triparia, refinaria e graxaria.

Ao passar por um tanque de decantação são removidos do efluente da Linha Vermelha os resíduos de menor densidade (constituídos em grande parte de gordura) que ascendem, e os sólidos sedimentáveis. Na sequência, o efluente é encaminhado às Lagoas de Estabilização.

O efluente da Linha Vermelha foi utilizado nos ensaios experimentais deste trabalho, sendo coletado em um ponto posterior a etapa de decantação e anterior ao tratamento biológico, conforme pode ser observado na Figura 1. Devido à localização do ponto de coleta, o efluente utilizado se encontrava livre de sólidos grosseiros e de grande parte da gordura.

Caracterizou-se o efluente quanto ao $\mathrm{pH}$, condutividade elétrica e Demanda Química de Oxigênio (DQO). Para calcular a eficiência do tratamento por wetland construído estes mesmos parâmetros foram determinados a partir da coleta de amostras do efluente em estudo a cada 24 horas. O experimento foi encerrado com um tempo de retenção hidráulica total de 96 horas.

Figura 1. Fluxograma do sistema de tratamento de efluente do frigorífico de suínos

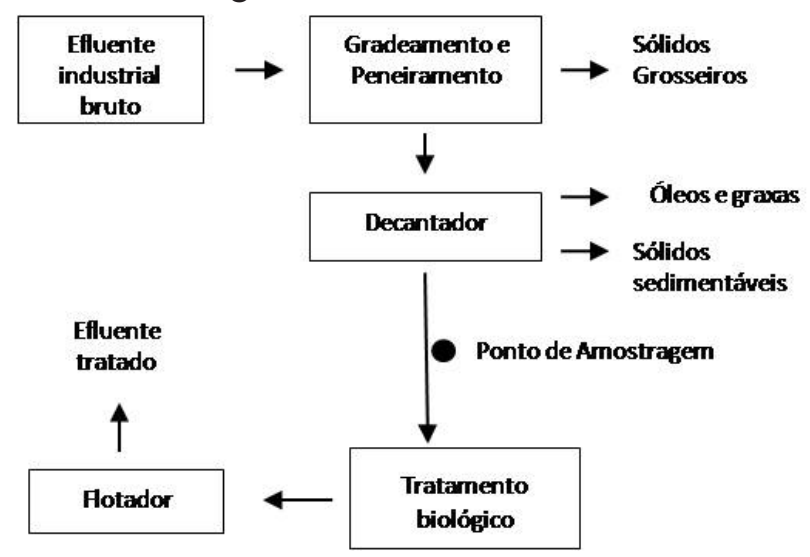

Fonte: Acervo dos autores

\section{Módulo Experimental}

$\mathrm{O}$ efluente industrial bruto coletado foi disposto em um recipiente plástico (30 litros) o qual ficou suspenso em uma bancada construída com aproximadamente 80 tijolos. Para que o efluente industrial escoasse para o módulo wetland construído foi utilizada uma mangueira flexível interligada entre a torneira do primeiro recipiente para os tubos do módulo experimental. 
O módulo experimental foi construído a partir de um recipiente plástico com capacidade de aproximadamente 50 litros, cortado longitudinalmente. Como material filtrante este módulo foi preenchido com uma camada de pedra brita de $5 \mathrm{~cm}$ de espessura, uma camada de areia de granulometria média/grossa de $10 \mathrm{~cm}$ de espessura seguido novamente por outra camada de pedra brita porém, com $10 \mathrm{~cm}$ de espessura, e na superfície uma fina camada de solo de modo a proporcionar a base para o plantio das plantas (Juncus effusus), as quais foram coletadas na fase adulta e transplantadas para o módulo experimental.

A alimentação do efluente industrial às raízes das plantas foi feita por dois canos de PVC de aproximadamente $40 \mathrm{~cm}$ de comprimento e $1 \mathrm{~cm}$ de diâmetro, instalados imediatamente abaixo da superfície. Tais canos foram perfurados para que proporcionassem uma distribuição uniforme para todo o módulo de tratamento. O efluente escoava por gravidade através das camadas filtrantes constituintes do sistema wetland, saindo do módulo por uma torneira adaptada em sua base. Na sequência o efluente era recolhido em outro recipiente plástico, o qual contava com um controlador de nível, ou seja, ao atingir um determinado nível pré-determinado, uma bomba era acionada, de modo a recircular o efluente. A água perdida por evaporação era reposta pelo acréscimo de água destilada.

O módulo experimental para o tratamento do efluente industrial por wetland construído pode ser observado na Figura 2:

Figura 2. Esquema do módulo experimental de tratamento de efluentes por wetland construído

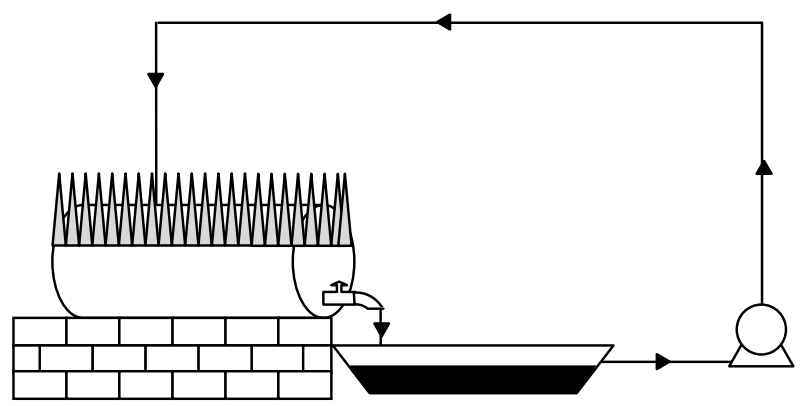

Fonte: Acervo dos autores
As análises físico-químicas foram realizadas em duplicata, e os métodos utilizados podem ser observados na Tabela 1:

Tabela 1. Métodos utilizados para as análises físico-químicas

\begin{tabular}{c|c|c}
\hline Parâmetro & Unidade & Método \\
\hline DQO & mg.L-1 & $\begin{array}{c}\text { (APHA, 2005) - } \\
\text { Colorimétrico }\end{array}$ \\
\hline $\mathrm{pH}$ & - & $\begin{array}{c}\text { Potenciométrico } \\
\mathrm{pHmetro}-\text { Marca } \\
\text { Hanna - Modelo } \\
\mathrm{pH} 21\end{array}$ \\
\hline $\begin{array}{c}\text { Condutividade } \\
\text { Elétrica }\end{array}$ & $\mathrm{mS} . \mathrm{cm}^{-1}$ & $\begin{array}{c}\text { Marca Digimed - } \\
\text { Modelo CD-21 }\end{array}$
\end{tabular}

Fonte: Acervo dos autores

\section{Resultados}

Para a avaliação dos resultados e cálculo da eficiência do tratamento do sistema por wetland construído estudado, foi realizada uma série de ensaios físicoquímicos com amostras, do efluente bruto (apenas com tratamento preliminar e primário, recebido antes do ponto de amostragem) e do efluente após o tratamento por sistema de wetland construído, com tempos de retenção hidráulica de 24, 48, 72 e 96 horas.

$\mathrm{Na}$ Tabela 2 são apresentados os resultados referentes a condutividade elétrica.

Tabela 2. Valores da condutividade elétrica para o efluente bruto e tratado pelo sistema de wetland construído

\begin{tabular}{|c|c|}
\hline Estágio de Tratamento & Condutividade $\left(\mathrm{mS} . \mathrm{cm}^{-1}\right)$ \\
\hline Efluente Bruto & $4,62 \pm 0,01$ \\
\hline Efluente Tratado por $24 \mathrm{~h}$ & $4,46 \pm 0,01$ \\
\hline Efluente Tratado por $48 \mathrm{~h}$ & $4,18 \pm 0,01$ \\
\hline Efluente Tratado por $72 \mathrm{~h}$ & $3,88 \pm 0,01$ \\
\hline Efluente Tratado por $96 \mathrm{~h}$ & $3,71 \pm 0,01$ \\
\hline
\end{tabular}

Fonte: Acervo dos autores 
Para uma melhor visualização dos valores médios de condutividade elétrica, estes são demonstrados na Figura 3.

Figura 3: Gráfico demonstrativo da variação da condutividade ao longo do período de tratamento

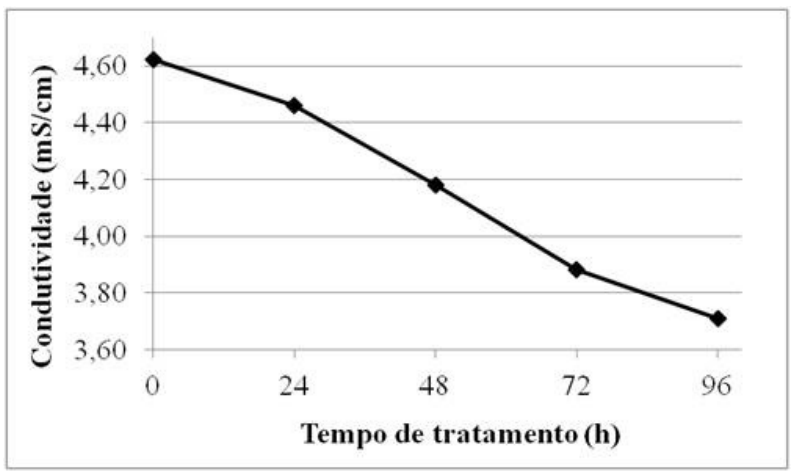

Fonte: Acervo dos autores

Na Tabela 3 são apresentados os resultados obtidos para o $\mathrm{pH}$ durante o período de tratamento do efluente, ressaltando-se que os limites preconizados pela Resoluções do CONAMA $357 / 2005$ e 430/2011 foram atendidos.

Tabela 3. Valores de $\mathrm{pH}$ para o efluente bruto e tratado pelo sistema de wetland construído

\begin{tabular}{cc}
\hline Estágio de Tratamento & $\mathbf{p H}$ \\
\hline Efluente Bruto & $6,73 \pm 0,01$ \\
Efluente Tratado por $24 \mathrm{~h}$ & $7,68 \pm 0,01$ \\
Efluente Tratado por 48 $\mathrm{h}$ & $7,95 \pm 0,01$ \\
Efluente Tratado por 72 $\mathrm{h}$ & $8,02 \pm 0,01$ \\
Efluente Tratado por 96 h & $8,15 \pm 0,01$ \\
\hline
\end{tabular}

Fonte: Acervo dos autores

Na Tabela 4 podem ser observados os resultados para a DQO do efluente ao longo do tratamento.

Os valores médios do $\mathrm{pH}$ em função do tempo de tratamento são demonstrados na Figura 4.
Figura 4. Gráfico demonstrativo da variação do $\mathrm{pH}$ ao longo do período de tratamento

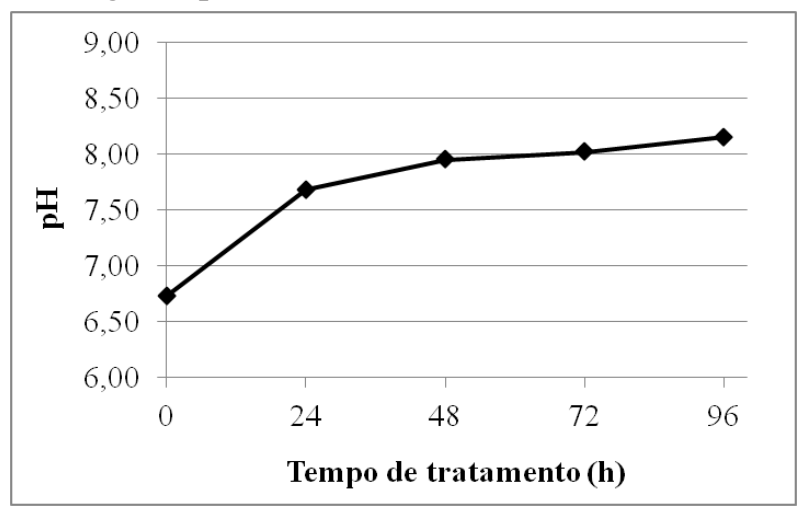

Fonte: Acervo dos autores

Tabela 4. Valores de DQO para o efluente bruto e tratado pelo sistema de wetland construído

\begin{tabular}{ccc}
\hline $\begin{array}{c}\text { Estágio de } \\
\text { Tratamento }\end{array}$ & DQO (mg.L $\left.\mathbf{~}^{-1}\right)$ & Remoção (\%) \\
\hline Efluente Bruto & $1900,5 \pm 84,0$ & 0,0 \\
Tratado por 24 h & $1481,2 \pm 9,9$ & $22,0 \pm 2,9$ \\
Tratado por 48 h & $337,8 \pm 16,7$ & $82,2 \pm 0,1$ \\
Tratado por 72 h & $198,1 \pm 12,2$ & $89,6 \pm 0,2$ \\
Tratado por 96 h & $30,1 \pm 10,1$ & $98,4 \pm 0,5$ \\
\hline
\end{tabular}

Fonte: Acervo dos autores

Os valores médios da DQO e da remoção desta podem ser melhor visualizados nas Figuras 5 e 6 , respectivamente.

Figura 5. Gráfico demonstrativo da variação da DQO ao longo do período de tratamento

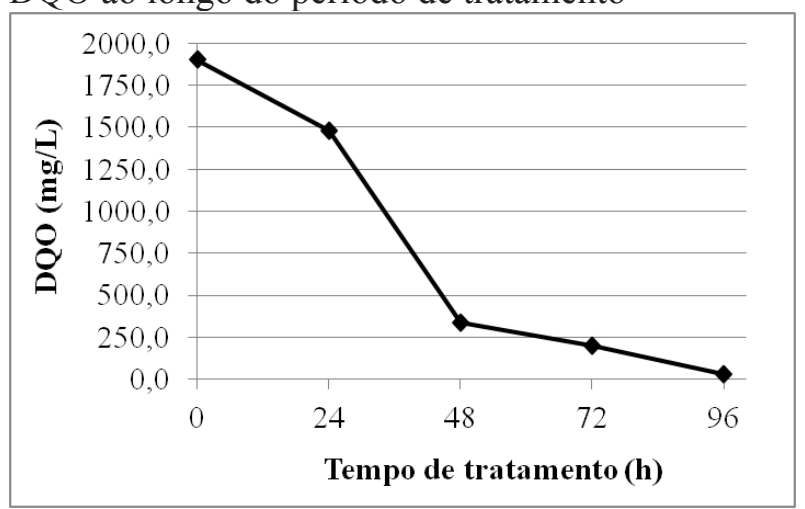

Fonte: Acervo dos autores 
Figura 6. Gráfico demonstrativo do percentual de remoção da DQO ao longo do período de tratamento

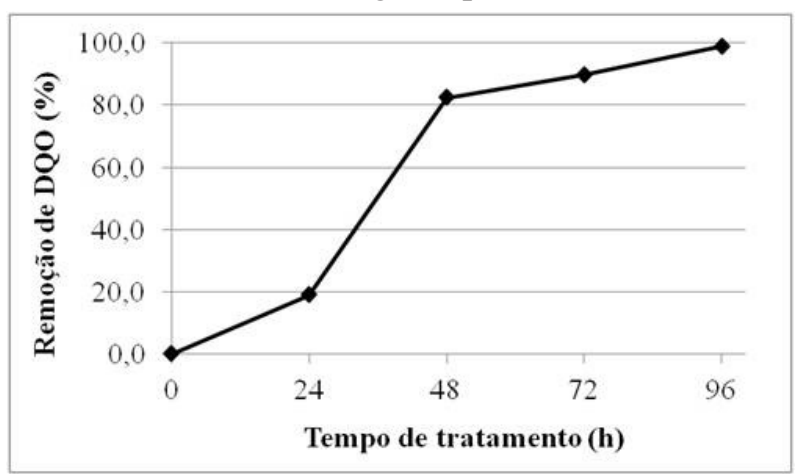

Fonte: Acervo dos autores

\section{Discussão}

Com relação aos dados apresentados na Tabela 2 , referentes a condutividade elétrica, é importante ressaltar que possivelmente dois fenômenos tenham ocorrido em paralelo, o consumo de nutriente por parte da planta retirando íons do meio, e reduzindo assim a condutividade elétrica e a estabilização da matéria orgânica, liberando para o meio, nutrientes na sua forma iônica, que antes estavam complexados. Assim, acredita-se que o consumo de nutrientes pela planta tenha sido razoável, sendo observada a queda na condutividade elétrica.

Analisando-se o $\mathrm{pH}$ do efluente ao longo do processo de tratamento por wetland construído, verifica-se (Tabela 3) que estes resultaram próximo à neutralidade e dentro dos padrões exigidos pela legislação ambiental (Resoluções CONAMA 357/2005 e 430/2011). Segundo Prata et al. (2013), faixas de $\mathrm{pH}$ próximas à neutralidade fornecem condições mais adequadas para degradação da matéria orgânica pelos microrganismos. Ressaltase ainda a alta eficiência alcançada na remoção da matéria orgânica, em um tempo de retenção hidráulica relativamente pequeno, demonstrado pelos dados de DQO apresentados na Tabela 4.

Diversas pesquisas vêm sendo realizadas utilizando-se wetlands construídos como alternativas para o pós-tratamento em efluentes de abatedouros ou frigoríficos que são altamente poluidores uma vez que possuem grande quantidade de material orgânico devido à presença de sangue, gordura, esterco e nutrientes, especialmente nitrogênio e fósforo (KREUTZ, 2012).

Matos et al. (2010) avaliaram a eficiência de wetlands plantados com Typha Latifolia L., Alternanthera philoxerooides e Cynodon dactylon Pers. no tratamento de água residuária de suinocultura e obtiveram eficiência média de remoção de $89 \%$ de matéria orgânica em termos de DQO, $52 \%$ de nitrogênio amoniacal e $50 \%$ de fósforo total.

Tavares et al. (2007) estudaram o desempenho da macrófita Lemna valdiviana plantada em um sistema wetland no tratamento terciário de efluente de suinocultura e chegaram a obter eficiência de $95 \%$ na remoção de matéria orgânica em termos de DQO.

Babatunde, Zhao e Zhao (2010) utilizaram lodo desidratado de uma estação de tratamento de água, como substrato em um sistema de wetland construído, empregando-se Phragmites australis. Os resultados foram promissores, com $90,6 \%$ de remoção para a DBO, 71,8\% para DQO, e 93,3\% para o fósforo.

Ghosh e Gopal (2010) estudaram o emprego do sistema de wetland construído com alimentação subsuperficial, verificando a influência de diferentes tempos de retenção hidráulica, na remoção de matéria orgânica e nutrientes, como tratamento terciário para águas residuárias. Os melhores resultados foram alcançados com tempo de retenção hidráulica de 4 dias.

Mees et al. (2009) estudaram a eficiência do tratamento, por sistema de wetland construído, do efluente de um frigorífico de suínos, sendo empregado um tempo de retenção hidráulica de 5 dias e plantas da espécie Eichhornia crassipes. Os resultados obtidos demonstraram as eficiências máximas de remoções: DQO de $77,2 \%$; DBO de $77,8 \%$; nitrogênio total de $87,9 \%$; nitrogênio amoniacal de $47,5 \%$ e fósforo total de $38,9 \%$. 
Os sistemas de wetlands têm sido utilizados no pós-tratamento de efluentes de processos anaeróbios. Segundo Calijuri et al. (2009), estes sistemas são constituídos por filtros de alta condutividade hidráulica que dão suporte ao crescimento de macrófitas e permitem a formação de um biofilme. Esse arranjo apresenta elevada capacidade de remoção de matéria orgânica (48 a 74\%) (VALENTIM, 2003), sólidos (cerca de $70 \%$ ), nutrientes (35 a 60\%) (CALIJURI et al., 2009) e patógenos (99,58 a 99,97\%) (ALMEIDA; OLIVEIRA; KLIEMANN, 2007).

Além destas características, outras vantagens como baixo custo de implantação, simplicidade de operação e auto sustentabilidade tornam estes sistemas uma alternativa para pós-tratamento de efluentes anaeróbios. Por outro lado, a maior desvantagem é a necessidade de grandes áreas para tratamento de grandes volumes quando comparados a filtros biológicos (BEDA, 2011; VALENTIM, 2003).

Utilizando a macrófita Typha latifólia em wetland no tratamento de efluente de frigorífico de aves com tempo de retenção hidráulica total de 72 horas com vazão de $4,16 \mathrm{~L} / \mathrm{h}$ com o objetivo de polimento final do efluente, Stiegemeier (2014) obteve eficiência de $92,32 \%$ de redução da turbidez, $83,62 \%$ de redução da DBO e 89,30\% de redução de nitrogênio constatando que o wetland é indicado como sistema de polimento final do efluente.

Nas condições em que foi desenvolvido, este trabalho pode indicar que o sistema de wetland construído também poderia ser uma alternativa para polimento final do efluente, pois como tratamento principal o sistema demandaria uma área de grande dimensão o que poderia inviabilizar financeiramente o sistema.

\section{Conclusões}

De acordo com os resultados obtidos, o sistema de tratamento por wetland construído, por meio da utilização do Juncus effusus se mostrou eficiente quando aplicado ao efluente de um frigorífico de suínos, de alta carga orgânica.

O sistema demonstrou eficiência na redução dos parâmetros físico-químicos e da matéria orgânica presentes no efluente industrial, enquadrando os parâmetros analisados aos padrões exigíveis pela legislação, reduzindo dessa forma a possibilidade de contaminação dos corpos hídricos receptores.

Foi possível observar uma redução da condutividade elétrica, possivelmente devido ao consumo dos nutrientes pela planta. Além disso, os valores obtidos para o $\mathrm{pH}$ resultaram próximos à neutralidade e ficaram dentro da faixa requerida pela legislação ambiental.

Com relação a redução de DQO, a eficiência do tratamento foi de $98,4 \%$, resultado obtido com tempo de retenção de 96 horas, em sistema de recirculação.

Por fim, os resultados encontrados com o experimento em escala de bancada utilizado foram promissores, e habilitam o sistema de tratamento a um novo experimento, em escala piloto. Além disso, dados quanto a autonomia do sistema proposto, ou seja, avaliação do tempo requerido para a saturação do filtro carecem de maiores estudos

\section{Referências}

ASSOCIAÇÃO BRASILEIRA DE PROTEÍNA ANIMAL. PRODUÇÃO MUNDIAL DE CARNE SUÍNA - ABPA. 2014. Disponível em: <http://abpabr.com.br/setores/suinocultura/ mercado-mundial $>$. Acesso em: 25 nov. 2015.

ALMEIDA, R. A.; OLIVEIRA, L. F. C.; KLIEMANN, H. J. Eficiência de espécies vegetais na purificação de esgoto sanitário. 2007. Tese (Doutorado em Agronomia) - Universidade Federal de Goiás, Goiânia.

AMERICAN PUBLIC HEALTH ASSOCIATION - APHA. Standard methods for examination of water and weatewater. 21. ed. Washington, DC: APHA, 2005. 
BABATUNDE, A. O.; ZHAO, Y. Q.; ZHAO, X. H. Alum sludge-based constructed wetland system for enhanced removal of $\mathrm{P}$ and $\mathrm{OM}$ from wastewater: Concept, design and performance analysis. Bioresource Technology, Essex, v. 101, p. 6576-6579, 2010.

BEDA, J. N. Determinação do coeficiente de decaimento bacteriano em Wetland (Alagado construído). 2011. 50 f. Dissertação (Mestrado em Engenharia Sanitária) - Universidade Federal do Rio Grande do Norte, Natal.

BRASIL, M. D. S.; MATOS, A. T. D. Avaliação de aspectos hidraúlicos e hidrológicos de sistemas alagados construídos de fluxo subsuperficial. Engenharia Sanitaria e Ambiental, Rio de Janeiro, v. 13, n. 3, p. 323-328, 2008.

CALIJURI, M. L. et al. Tratamento de esgotos sanitários em sistemas reatores UASB/wetlands construídas de fluxo horizontal: eficiência e estabilidade de remoção de matéria orgânica, sólidos, nutrientes e coliformes. Engenharia Sanitaria e Ambiental, Rio de Janeiro, v. 14, n. 3, p. 421-430, set. 2009.

CONSELHO NACIONAL DO MEIO AMBIENTE - CONAMA. Resolução $N^{\circ}$ 357, de 17 de março de 2005. Dispõe sobre a classificação dos corpos de água e diretrizes ambientais para o seu enquadramento. Disponível em: <http://www.mma. gov.br/port/conama/legiabre.cfm?codlegi $=459>$. Acesso em: 3 dez. 2015.

Resolução no 430, de 13 de maio de 2011. Dispõe sobre as condições e padrões de lançamento de efluentes. Disponível em: <http://www.mma. gov.br/port/conama/legiabre.cfm?codlegi $=646>$. Acesso em: 3 dez. 2015.

GHOSH, D.; GOPAL, B. Effect of hydraulic retention time on the treatment of secondary effluent in a subsurface flow constructed wetland. Ecological Engineering, Oxford, v. 36, p. 1044-1051, 2010.

GOUVEIA, A. F.; MACRUZ, P. D.; ARAÚJO, J. H. B. Fitorremediação de solos contaminados com Chumbo utilizando Jatropha curcas L. In: CONGRESSO BRASILEIRO DE ENGENHARIA QUÍMICA, 22., 2014, Florianópolis. Anais... São Paulo: Blucher, 2015. p. 8213-8219.
KREUTZ, C. Comportamento de reator anaeróbioaeróbio no tratamento de efluente bovino. 2012. 114 f. Tese (Doutorado em Engenharia Agrícola) - Universidade Estadual do Oeste do Paraná, Cascavel.

MATOS, A. T. et al. Capacidade extratora de plantas em sistemas alagados utilizados no tratamento de águas residuárias de laticínios. Revista Brasileira de Engenharia Agrícola e Ambiental, Campina Grande, v. 14, n. 12, p. 1311-1317, 2010

MEES, J. B. R. et al. Removal of organic matter and nutrients from slaughterhouse wastewater by using Eichhornia crassipes and evaluation of the generated biomass composting. Engenharia Agrícola, Jaboticabal, v. 29, n. 3, p. 466-473, 2009.

PENA, L. M. A. Depuração de efluente suinícola por Lemna minor e valorização energética da biomassa por co-digestão anaerobia. 2014. $47 \mathrm{f}$. Dissertação (Mestrado em Engenharia do Ambiente) - Universidade de Lisboa, Instituto Superior de Agronomia, Lisboa.

PEREIRA, F. J. Características anatômicas e fisiológicas de aguapé e índice de fitorremediação de alface d'água cultivados na presença de arsênio, cádmio e chumbo. 2010. 116 f. Tese (Doutorado em Agronomia/Fisiologia Vegetal) - Universidade Federal de Lavras.

PRATA, R. C. C. et al. Tratamento de esgoto sanitário em sistemas alagados construídos cultivados com lírio-amarelo. Engenharia Agrícola, Jaboticabal, v. 33, n. 6, p. 1144-1155, nov./dez. 2013.

PRATAS, J. et al. Acumulação de urânio em plantas aquáticas (região uranífera das Beiras): possibilidades de bioindicação e fitorremediação. Revista Electrónica de Ciências da Terra Geosciences, Vila Real, v. 9, n. 15, p.1-4, 2010.

SCHOENHALS, M.; SENA. R. F.; JOSÉ. H. J. Avaliação da eficiência do processo de coagulação/ flotação aplicado como tratamento primário de efluentes de abatedouro de frangos. Engenharia Ambiental, Espírito Santo do Pinhal, v. 3, n. 2, p. 5-24, jul./dez. 2006. 
SEZERINO, P. H. et al. Wetlands construídos horizontais aplicados no tratamento descentralizado de esgotos. In: SIMPÓSIO BRASILEIRO SOBRE WETLANDS CONSTRUÍDOS, 2., 2015, Curitiba, Anais... Curitiba, 2015.

SOUZA, C. F. et al. Eficiência de estação de tratamento de esgoto doméstico visando reuso agrícola. Revista Ambiente \& Água, Taubaté, v. 10, n. 3, jul./ set. 2015.

SOUZA, J. T. et al. Pós-Tratamento de efluente de reator UASB utilizando sistemas "Wetlands" construídos. Revista Brasileira de Engenharia Agrícola e Ambiental, Campina Grande, v. 4, n. 1, p. 87-91, 2000.

SOUZA, V. C.; LORENZI, H. Botânica sistemática: guia ilustrado para identificação das famílias de angiospermas da flora brasileira, baseado em APG II. Nova Odessa: Instituto Plantarum, 2005.

STIEGEMEIER, A. M. Avaliação do sistema wetland construído no polimento do efluente da indústria frigorífica de aves. 2014. Monografia (Especialização em Engenharia Ambiental) Centro Universitário Univates, Lajeado.

TAVARES, F. A. et al. Desempenho da macrófita Lemma valdiviana no tratamento terciário de efluentes de suinocultura e sua contribuição para a sustentabilidade da atividade. 2007. Revista Biotemas, Florianópolis, v. 21, n. 1, mar. 2008.

TOET, S. et al. Denitrification in the periphyton associated with plant shoots and in the sediment of a wetland system supplied with sewage treatment plant effluent. Biomedical and Life Sciences, v. 501, n. 1, p. 29-44, 2003.

TRANG, N. T. D. et al. Kinetics of pollutant removal from domestic wastewater in a tropical horizontal subsurface flow constructed wetland system: Effects of hydraulic loading rate. Academic Search Premier, v. 36, n. 4, p. 527-535, 2010.

VALENTIM, M. A. A. Desempenho de leitos cultivados ("Constructed Wetland") para tratamento de esgoto: contribuições para concepção e operação. 2003. 233 f. Tese (Doutorado em Engenharia Agrícola) - Universidade Estadual de Campinas, Faculdade de Engenharia Agrícola, Campinas. 
